\title{
Commentary: Aortic mural leiomyosarcoma with spinal involvement: Surgeons of different specialties...let's get together
}

\author{
Jean Bachet, MD, FEBCTS
}

\author{
$\overline{\text { From ADETEC }}$, Suresnes, France. \\ Disclosures: Author has nothing to disclose with regard to commercial support. \\ Received for publication April 13, 2019; revisions received April 13, 2019; accepted for publication April 15, \\ 2019; available ahead of print June 18, 2019. \\ Address for reprints: Jean Bachet, MD, FEBCTS, 1 Place Marcel Legras, 92150 Suresnes, France (E-mail: Jean. \\ bachet@yahoo.fr). \\ J Thorac Cardiovasc Surg 2020;159:e255 \\ $0022-5223 / \$ 36.00$ \\ Copyright (c) 2019 by The American Association for Thoracic Surgery \\ https://doi.org/10.1016/j.jtcvs.2019.04.090
}

In their article, Kawashima and co-workers ${ }^{1}$ report 3 cases of a rare pathologic aortic condition who underwent successful operation.

This well-written article is interesting because of the rarity of the described lesions (I have never observed such a lesion in 40 years of aortic surgery!), the detailed description of the surgical treatment, and the good images provided to the readers. The authors are to be congratulated for undertaking such difficult surgical procedures with no immediate mortality, although they indicate that in their experience and in the reported literature, the nature of such lesions has led systematically to a midterm lethal outcome.

Nevertheless, one may observe that the patients did not undergo systematically a total resection of the diseased part of the aorta (except in case 3) and that stent grafting leaving the aortic wall was used in case 1, whereas nothing was done on the aorta in case 2 .

This raises an important and somewhat delicate question: By whom and how those severe lesions involving several totally different anatomic structures (ie, the aorta, spinal cord, and vertebras) should undergo operation?

In this reported experience, the patients have been diagnosed and treated in an orthopedic department, and it seems obvious that the orthopedic and neurologic consequences of the disease were in the forefront of the team's concerns and strategy. In 2 cases, emergency surgery to decompress the spinal cord was carried out to avoid impending paraplegia. The aortic problem was kept in the background. Stenting the aorta in case 1 was performed only to avoid bleeding during resection of the tumor and the very limited resection of the aortic wall, whereas nothing was done on the aorta in case 2 . Only in case 3 , the aorta was the cause of the emergency procedure.

One may wonder whether such patients undergoing operation in a department of cardiovascular surgery with some experience in aortic surgery would have received the same procedures.

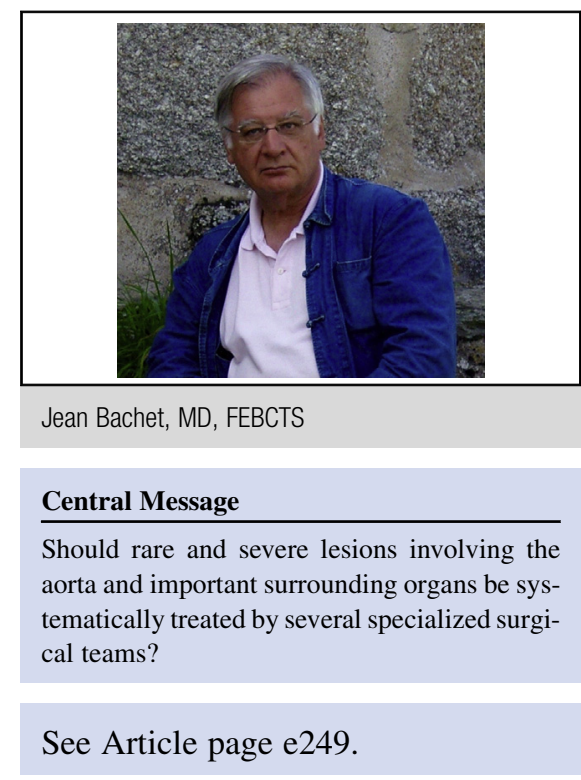

It seems somewhat likely that the procedure, emergency or not, would have consisted in a large replacement of the thoracic or thoracoabdominal aorta with the tumor and that the vertebral problem would have been treated subsequently, either immediately or during a staged procedure by an orthopedic team. The risk of paraplegia would have possibly been considered as less important than the vascular and tumor one.

Yet and of course, it is by no means certain that the immediate and midterm outcomes would have been more favorable than those obtained in the reported experience.

Nevertheless, it is rather interesting to observe how the surgical teams are, in a certain way, conditioned through their education, training, experience, and daily practice to rank and prioritize the pathologic disturbances and diseases they have to deal with and the way to manage those, especially when they are unusual, severe, or life threatening.

Therefore, it seems evident that such conditions and strategies should systematically be analyzed, discussed, decided, and carried out by all the teams of various specialties that could be involved in the treatment.

\section{Reference}

1. Kawashima H, Ariizumi T, Ogose A, Umezu H, Okamoto T, Oike N, et al. Aortic mural leiomyosarcoma with spinal involvement. J Thorac Cardiovasc Surg. 2020; 159:e249-53. 